\title{
Comparative Study on Card Yarn Properties Produced from Conventional Ring and Compact Spinning
}

\author{
Rajib Al Mamun', Md. Reazuddin Repon ${ }^{1, *}$, Mohammad Abdul Jalil ${ }^{2}$, Ahmed Jalal Uddin ${ }^{3}$ \\ ${ }^{1}$ Department of Textile Engineering, Khwaja Yunus Ali University, Bangladesh \\ ${ }^{2}$ Department of Textile Engineering, Khulna University of Engineering \& Technology, Bangladesh \\ ${ }^{3}$ Department of Textile Engineering, Ahsanullah University of Science \& Technology, Bangladesh
}

Copyright $\bigcirc 2017$ by authors, all rights reserved. Authors agree that this article remains permanently open access under the terms of the Creative Commons Attribution License 4.0 International License

\begin{abstract}
Yarn characteristics extensively influence by spinning process. The aim of this study is to observe the effect of conventional ring and compact spinning processes on properties of yarn. $100 \%$ CIS-Turkey cotton was used to produce conventional ring card yarn and card compact yarn. The twist per inch of 16.99 and 19.57 were settled to fabricate $20 \mathrm{Ne}$ and $30 \mathrm{Ne}$ count of yarn respectively both for conventional ring and compact spinning. The positive effect of spinning process on the yarn properties were evaluated by co-efficient of variation (CVm \%), imperfection index (IPI), hairiness, tenacity, count strength product (CSP) and elongation (\%). The results exposed that yarn qualities of compact spinning were exhibited higher than conventional ring spinning.
\end{abstract}

Keywords Conventional Ring Spinning, Compact Spinning, Hairiness, Imperfection, Yarn Strength

\section{Introduction}

Spinning is the process of producing yarn from various raw fibre materials. Characteristics of the yarn differ based on the material used, fibre length, alignment, quantity of fibre used and degree of twist [1]. On the other hand, achievement of improved yarn quality is the main goal of any spinning company that will ensure better competitiveness.

Development efforts in ring spinning were focused on improving the existing technology and incorporating automation and process-linking capabilities. The advancement of spinning technology has generally altered the relationships between fiber properties and yarn quality. Different spinning processes are likely to involve different fiber-machine interactions, which in turn alter the optimum combinations of fiber properties [2].

Compact spinning is a modified version of ring spinning. This system is oriented to better fiber utilization and the high quality rather than higher productivity $[3,4]$. Compact spinning produce novel yarn structure by applying air suction to condense the fiber stream in the main drafting zone. Compact spinning can be used in both short- and long-staple yarn spinning areas [5].

In conventional ring spinning, the zone between the nip line of the pair of delivery rollers and the twisted end of the yarn is called the "spinning triangle" which represents the critical weak spot of this process. The fibre assembly contains no twist in this zone. The edge fibers lead to the familiar problem of yarn hairiness [5-7]. But in compact spinning, the fibres which have left the drafting system are guided via the perforated drums over the openings of the suction slots. Following the air flow, the fibers move sideways and are consequently condensed. This condensing has such a favorable effect on the ratio of the width of the condensed fibre to yarn diameter that the spinning triangle is nearly eliminated (figure 1). Almost all the fibres are incorporated into the yarn structure under the same tension when spinning is done without spinning triangle. As the twist insertion takes place very close to the nip line, short fibers can take up tension. Therefore, the yarn strength is increased as more fibres contribute to the yarn structure. [5, 6, 8-10]. The fly and dust reduction is occurred as an effect of condensation. The cleaning requirement is reduced compare to conventional ring spinning frames.

In compact yarns, fibres are uniformly oriented and joined into the yarn right after the end of the drafting arrangement. Therefore, better tenacity, elongation, and hairiness properties can be ensured. The better tenacity properties of compact spun yarn provide opportunities to work with lower twist coefficients, resulting in an increase in production rate, and also better handling properties of the end product $[5,11]$.

Many researchers have described the technical principles of compact spinning and ring spinning. The physical and mechanical properties of compact yarn and ring spun yarn have also studied. The compact yarn shows higher strength, reduced hairiness, and improved evenness. Test results concluded that the qualities of compact yarns are better than ring-spun yarns [12-18]. 
The objectives of this exploration were to produce quality yarn and analyze the test results and finally compare the properties of cotton yarns produced by compact spinning systems with the conventional ring yarns. The yarn quality on the basis of co-efficient of variation ( $\mathrm{CVm} \%)$, imperfection index (IPI), hairiness, tenacity, count strength product (CSP) and elongation (\%) were investigated and discussed analytically.

\section{Materials and Methods}

\subsection{Materials}

Carded rovings of $100 \%$ CIS-Turkey cotton having 0.84 $\mathrm{Ne}$ and $0.75 \mathrm{Ne}$ were collected for producing $20 \mathrm{Ne}$ and 30 Ne yarn respectively from "Talha Spinning Mills Limited" Gazipur, Bangladesh. Table 1 indicates the CIS-Turkey cotton fibre properties used in this experiment those were assessed by Uster- HVI instrument at standard testing condition [20].

Table 1. Fiber properties of CIS-Turkey cotton

\begin{tabular}{|c|c|}
\hline Quality parameters & Value \\
\hline Spinning Consistency Index & 144 \\
\hline Mic $(\mu \mathrm{g} /$ inch) & 4.32 \\
\hline Maturity & 0.90 \\
\hline Length (mm) & 29.85 \\
\hline Uniformity Index & 82.0 \\
\hline Short Fibres Index (\%) & 7.2 \\
\hline Strength (gm/Tex) & 33.9 \\
\hline Elongation (\%) & 7.0 \\
\hline Moisture (\% ) & 7.1 \\
\hline Reflectance (\%) & 77.6 \\
\hline Yellowness (+b) & 10.3 \\
\hline Trash content & 22 \\
\hline
\end{tabular}

\subsection{Methods}

\subsubsection{Sampling}

Different samples are identified as mentioned table 2.

Table 2. Sample Identification

\begin{tabular}{|c|c|}
\hline Sample types & Identification \\
\hline $\begin{array}{c}\text { Card yarn of } 20 \text { Ne from conventional } \\
\text { ring spinning }\end{array}$ & A \\
\hline $\begin{array}{c}\text { Card compact yarn of } 20 \mathrm{Ne} \text { from } \\
\text { compact spinning }\end{array}$ & B \\
\hline $\begin{array}{c}\text { Card yarn of } 30 \text { Ne from conventional } \\
\text { ring spinning }\end{array}$ & C \\
\hline $\begin{array}{c}\text { Card compact yarn of } 30 \text { Ne from } \\
\text { compact spinning }\end{array}$ & D \\
\hline
\end{tabular}

\subsubsection{Testing of Samples}

Uster Tester- 5 was used to determine the unevenness and imperfection (IPI) of the yarn at a speed of $450 \mathrm{~m} / \mathrm{min}$. The observed parameters were $\mathrm{CVm} \%$, thin places $(-50 \%)$, thick places $(+50 \%)$, neps $(+280 \%)$ and hairiness. The imperfection (IPI) is the sum of number of mass increase (thick places), mass reductions (thin places), and short mass increases (neps).Tensile properties viz., yarn tenacity, count strength product (CSP) and elongation (\%) were measured at Uster Tensojet-4 at a speed of $200 \mathrm{~m} / \mathrm{min}$. Average of ten tests were taken for final result at each trial. All experiments were performed at temperature $20 \pm 2{ }^{\circ} \mathrm{C}$ and relative humidity $65 \pm 2 \%$.

Yarn count was determined through the digital auto sorter-5 linked with compute system, which gives direct reading. Lea strength tester was used to find the lea strength in pounds according to the ASTM (1997) method. Count strength product (CSP) was calculated by multiplying the yarn count with Lea strength according to the British Standard (1985). Equation 1 was used to measure CSP.

$$
\text { CSP }=\text { Yarn count } \times \text { Lea strength }
$$

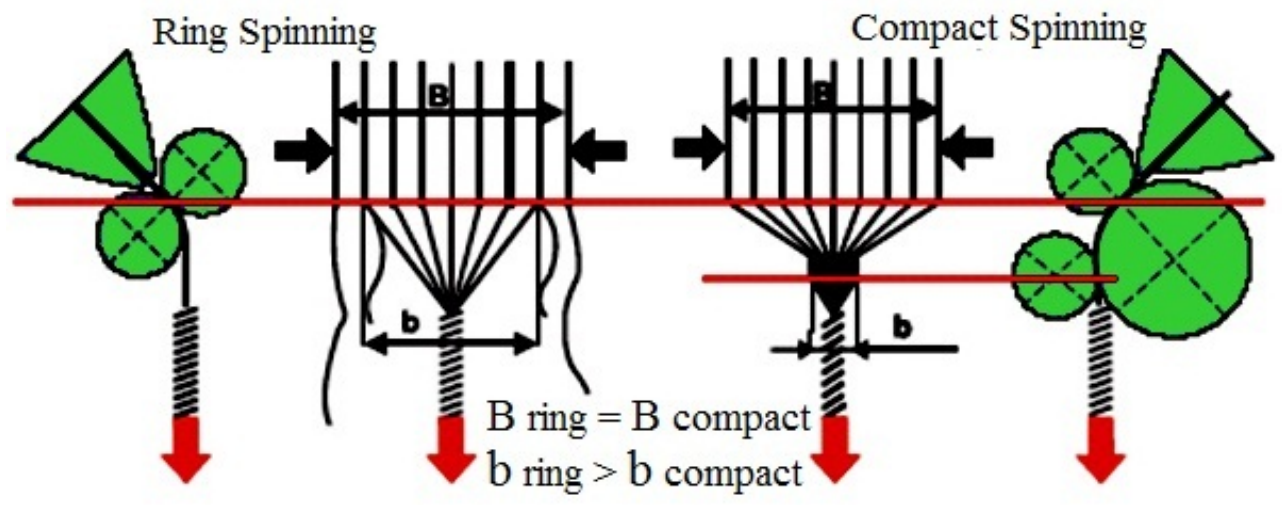

Figure 1. Operating principles of conventional ring spinning and compact spinning [19] 
Fibre

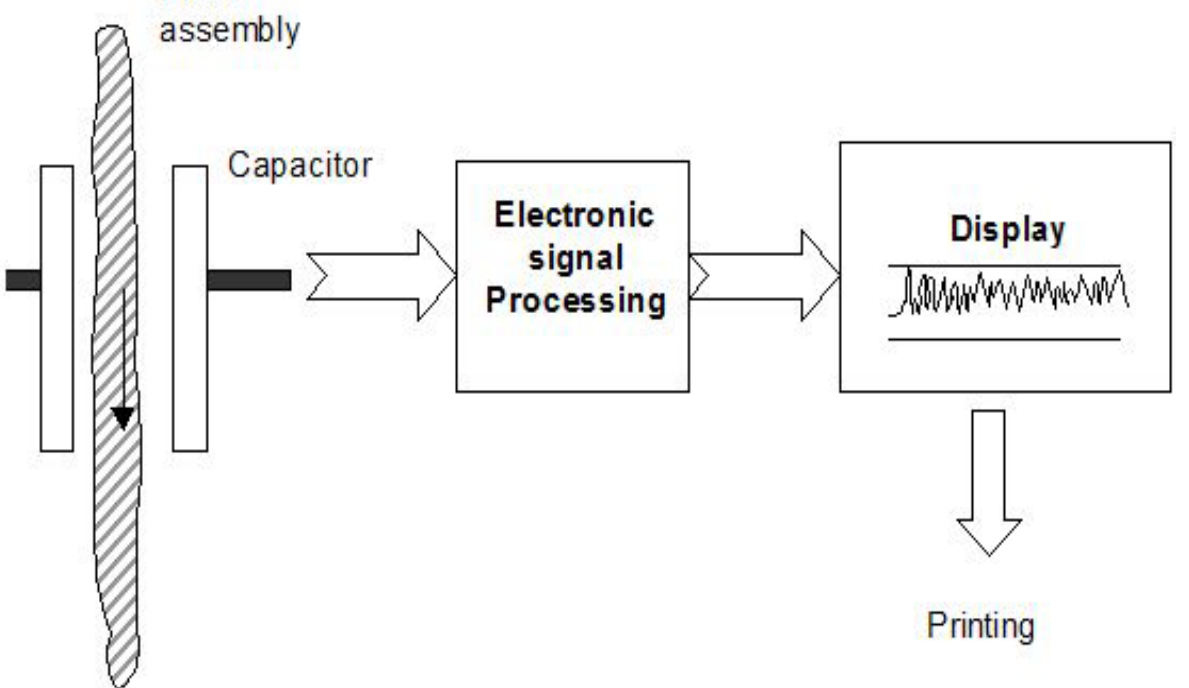

Figure 2. Principle of Uster evenness tester [21]

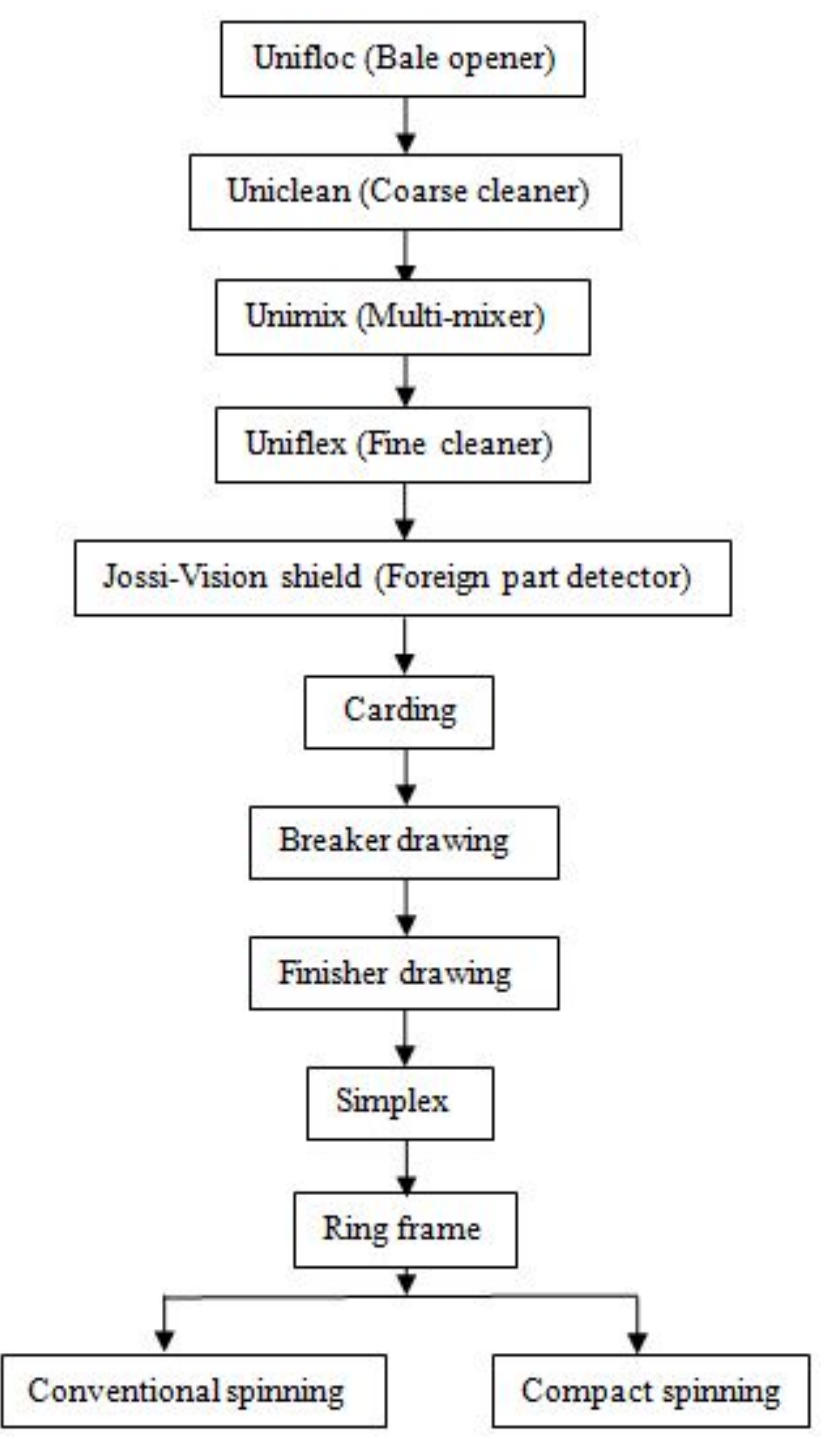

Figure 3. Flow diagram of yarn preparation 


\subsubsection{Machine Parameters Settings}

Toyota RX240 ring frame (Japan) was used for conventional spinning process and comfort Spin machine K 44 (Switzerland) used for compact spinning system. Table 3 indicates the machine parameters settings of conventional and compact ring spinning frame.

Table 3. Parameters settings of conventional and compact ring spinning frame

\begin{tabular}{|c|c|}
\hline Conventional spinning & Compact spinning \\
\hline $\begin{array}{l}\text { Spindle speed: } 16500 \mathrm{rpm} \\
\text { Gauge setting: } \\
\text { Back to middle- } 58 \mathrm{~mm} \text { and } \\
\text { Middle to front- } 44 \mathrm{~mm} \\
\text { Spacer: } \\
\text { Color- yellow, Size }-2.2 \mathrm{~mm} \\
\text { Traveler: } \\
\text { Type- C, Tr. No. } 3 / 0 \\
\text { Ring dia.- } 42 \mathrm{~mm} .\end{array}$ & $\begin{array}{l}\text { Spindle speed: } 16500 \mathrm{rpm} \\
\text { Recommended vacuum-26Mbar } \\
\text { Gauge setting: } \\
\text { Back to middle- } 65 \mathrm{~mm} \text { and } \\
\text { Middle to front- } 53 \mathrm{~mm} \\
\text { Spacer: } \\
\text { Color- yellow, Size }-3.3 \mathrm{~mm} \\
\text { Traveler: } \\
\text { Type- C, Tr. No. } 3 / 0 \\
\text { Ring dia.- } 42 \mathrm{~mm}\end{array}$ \\
\hline
\end{tabular}

Figure 4. Conventional ring and compact yarn structure [22].

\subsubsection{Diameter Measurement}

The diameter of conventional and compact ring spun yarn was measured by Uster tester 4 . The OM module mounted on model, 4-SX is capable of measuring yarn diameter with dual light beams perpendicular to each other [23]. The diameter of $20 \mathrm{Ne}$ was found as $0.203 \mathrm{~mm}$ for ring yarn and $0.194 \mathrm{~mm}$ for compact yarn. Similarly, the diameter of $30 \mathrm{Ne}$ was observed $0.166 \mathrm{~mm}$ for ring yarn and $0.158 \mathrm{~mm}$ for compact yarn.

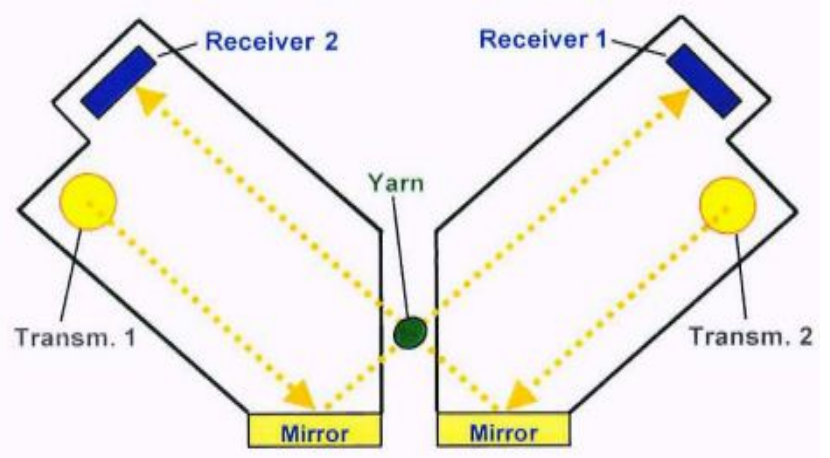

Figure 5. Principle of OM sensor of Uster 4 [24].

\section{Results and Discussion}

\subsection{Yarn Unevenness}

\subsubsection{Irregularity $\mathrm{CVm} \%$}

The figure 6 represents the $\mathrm{CVm} \%$ of the conventional ring spun yarn and card compact yarn. $\mathrm{CVm} \%$ was showed relatively lower in compact yarn than conventional ring spun yarn in same count. For $20 \mathrm{Ne}$ yarn, the $\mathrm{CVm} \%$ were $7.16 \%$ decreased for the sample B as compared to $\mathrm{A}$. It has been also found that the $\mathrm{CVm} \%$ were decreased $2.39 \%$ for the samples $\mathrm{D}$ compared to the sample $\mathrm{C}$ at $30 \mathrm{Ne}$ yarn. It is clearly evident that the compact spinning offers more regular and even yarns than conventional ring spinning. Conversely, $\mathrm{CVm} \%$ was increased with the increase of yarn count both for conventional ring card and card compact yarn. The $\mathrm{CVm} \%$ increased $15.78 \%$ and $21.72 \%$ for conventional ring yarn and card compact yarn respectively during raising the yarn count from 20 to $30 \mathrm{Ne}$.

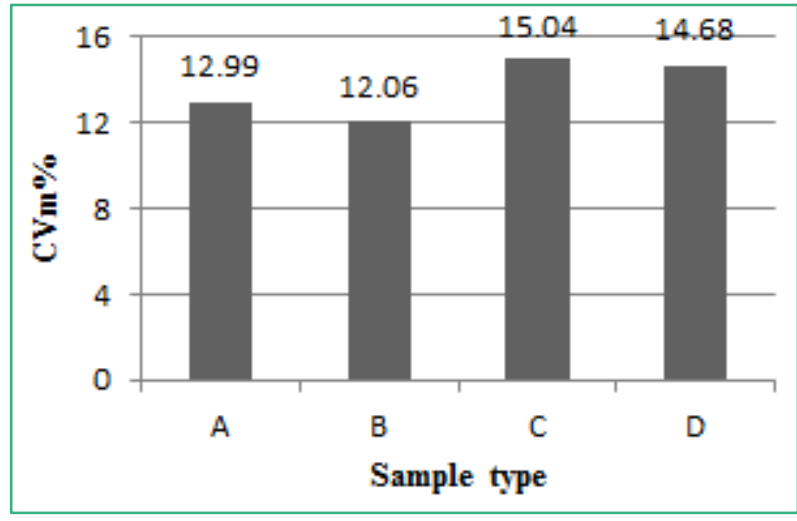

Figure 6. Effect of conventional ring and card compact yarn on $\mathrm{CV} \%$

\subsubsection{Imperfection}

Figure 7 shows the effect of spinning process on yarn imperfections properties. The yarn imperfections values were decreased for card compact yarn. For $20 \mathrm{Ne}$ yarn, the imperfections were decreased $64.90 \%$ for the sample B as compared to A. Similarly for $30 \mathrm{Ne}$ yarn, the imperfections values were decreased $25.25 \%$ for D compared to $\mathrm{C}$. The imperfections were increased with increase the yarn count both for conventional ring card yarn and card compact yarn. The $\mathrm{CVm} \%$ were increased $90.38 \%$ for $\mathrm{D}$ and $305.79 \%$ increased $\mathrm{C}$ compared to $\mathrm{A}$ and $\mathrm{B}$ respectively.

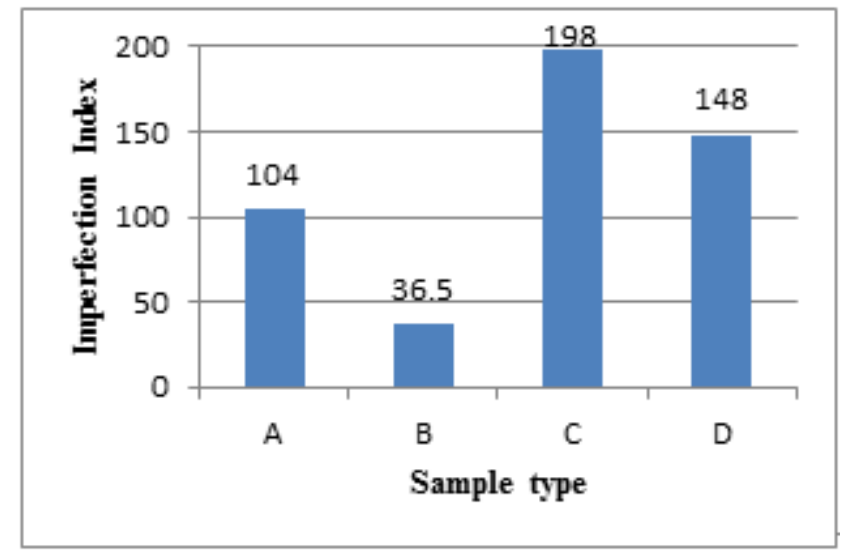

Figure 7. Effect of conventional ring and card compact yarn on imperfection 


\subsubsection{Hairiness}

The yarn hairiness is one of the most important parameters influences the performance of subsequent processes, appearance and end use of the final fabric. Figure 8 illustrates the yarn hairiness of conventional ring card yarn and card compact yarn. In compact spinning, less hairy and more even yarns were produced than conventional ring spinning. The hairiness was decreased $14.90 \%$ for B and $19.77 \%$ decreased for $\mathrm{D}$ contrast to $\mathrm{A}$ and $\mathrm{C}$ respectively. It was also found that the hairiness was $19.20 \%$ decreased for $\mathrm{C}$ and $23.83 \%$ increased for D compare to A and B correspondingly.

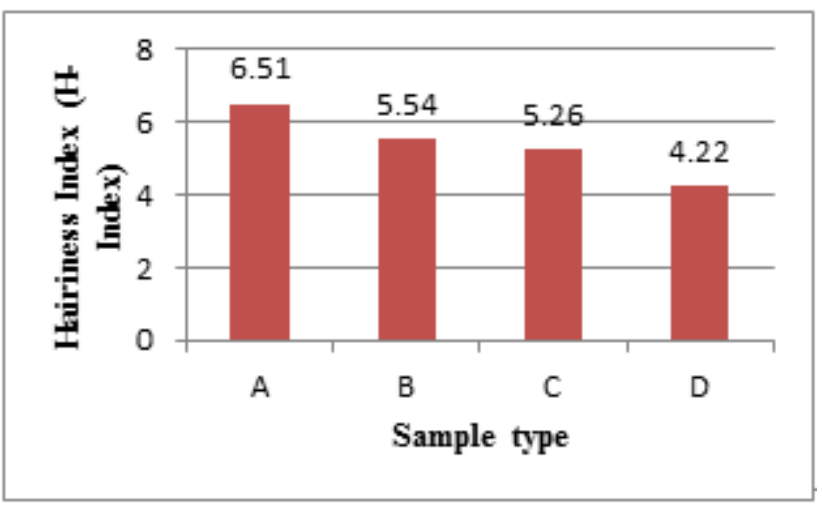

Figure 8. Effect of conventional ring and card compact yarn on hairiness

\subsection{Yarn Strength}

\subsubsection{Tenacity}

Figure 9 clarify the effect of conventional ring spinning and compact spinning on yarn tenacity. The tenacity of yarn produced from compact spinning showed higher than the conventional ring spun yarn. The values of tenacity were increased $4.14 \%$ for B and $7.77 \%$ increased for D respect to $\mathrm{A}$ and $\mathrm{C}$ respectively. Equally, higher count yarn showed higher tenacity. The tenacity 3.69\% increased for $\mathrm{C}$ and $7.31 \%$ increased D compare to A and B correspondingly.

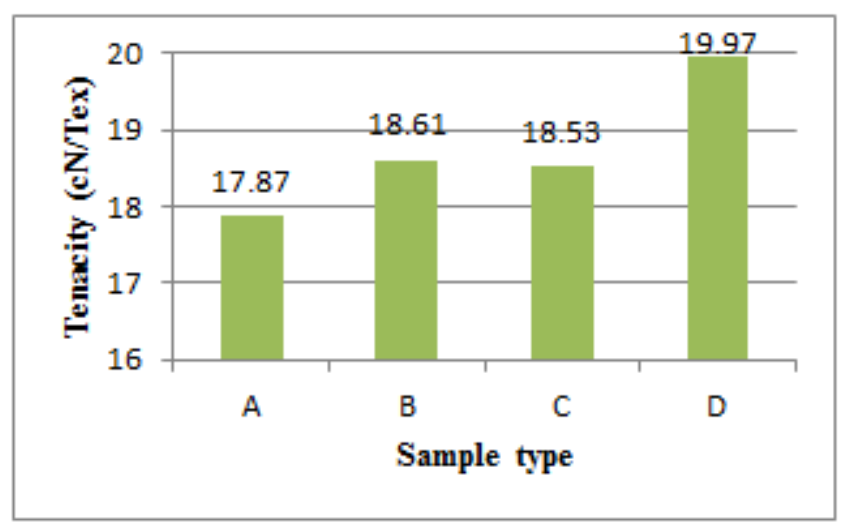

Figure 9. Effect of conventional ring and card compact yarn on tenacity

\subsubsection{Count Strength Product}

Spinning methods have significant effect on the yarn count strength product (CSP) of yarn. From figure 10, it is clearly evident that, the CSP value showed higher in case of compact yarn than conventional ring card yarn. The CSP value were increased $4.14 \%$ for B compared to A and $7.77 \%$ increased for D with respect to C. Conversely, the CSP value were increased $3.69 \%$ for $\mathrm{C}$ and $7.31 \%$ increased for $\mathrm{D}$ compared to $\mathrm{A}$ and $\mathrm{B}$ respectively due to increasing yarn count from $20 \mathrm{Ne}$ to $30 \mathrm{Ne}$.

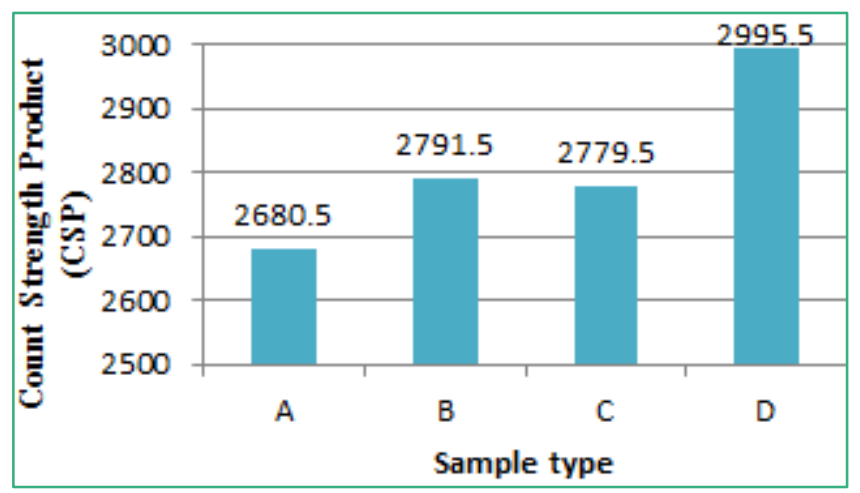

Figure 10. Effect of conventional ring and card compact yarn on CSP

\subsubsection{Elongation (\%)}

Figure 11 demonstrates the elongation (\%) of conventional ring card yarn and card compact yarn. The card compact yarn exhibited higher value of elongation percentage than conventional ring spun yarn. The elongation $23.48 \%$ increased for B and $21.20 \%$ increased for D respect to sample $\mathrm{A}$ and $\mathrm{C}$ respectively. Elongation percentage also increased with the increase of yarn count both for conventional ring and compact spinning. The elongation $9.59 \%$ increased for conventional ring and $7.57 \%$ increased for compact spinning due to increase of yarn count from 20 $\mathrm{Ne}$ to $30 \mathrm{Ne}$.

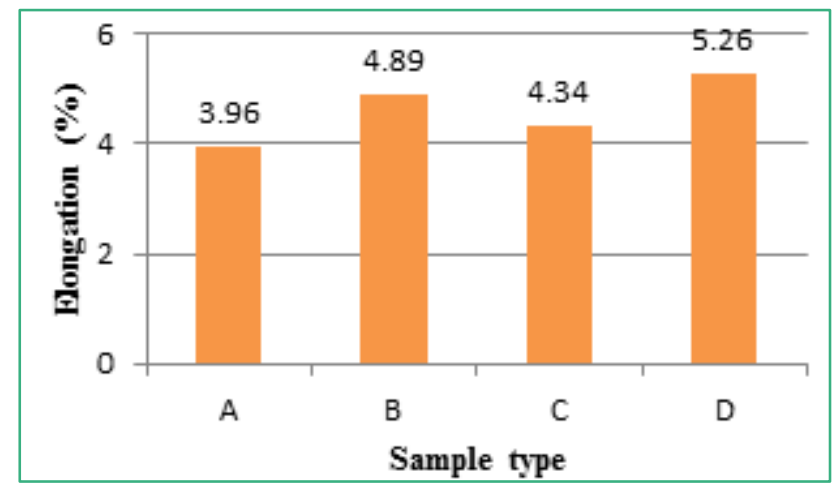

Figure 11. Effect of conventional ring and card compact yarn on elongation $\%$

\section{Conclusions}

The properties of conventional ring card yarn and card compact yarn were studied in terms of $\mathrm{CVm} \%$, total imperfection index (IPI), hairiness, tenacity, CSP and elongation\%. The overall results showed that the compact 
yarns have lower $\mathrm{CVm} \%$, less Imperfection Index (IPI), lower hairiness, higher tensile strength and elongation $\%$, and higher Count Strength Product (CSP) than conventional ring card yarns. These studies revealed the consistent results of reduced yarn hairiness, the ability to produce yarns of enhanced better strength and elongation properties even with a less amount of twist, which enables increased production speeds to be reached in favor of the compact spinning system. Further work could be done on producing quality yarn of various counts from other natural, synthetic and blends fibres to justify this analysis. Finally, it is recommended that if it is possible to reduce the maintenance cost then the compact spinning will be the best one spinning system to produce better quality of yarn.

\section{REFERENCES}

[1] Afrose Fathima Farid, Roshanara, V. Subramaniam, Effect of Chemical Treatments on the Characteristics of Regular and Compact Cotton Spun Yarns, International Journal of Research in Engineering and Technology, 03(11), 43-51, 2014.

[2] Ethridge, D. and Krifa, M., Compact Spinning Effect on Cotton Yarn Quality Interactions with Fiber Characteristics, Textile Research Journal, 76(5), 388-399, 2006.

[3] Artzt, P., Short staple spinning on the way to new yarn structures and better raw material utilization, International Textile Bulletin, 45 (4), 16-23, 1999.

[4] Stalder, H., New spinning process ComforSpin, Melliand Textilberichte International Textile Reports, 81(3), 133-136, 2000.

[5] Çelik, P. and Kadoglu, H., A research on the compact spinning for long staple yarns. Fibres \& Textiles in Eastern Europe, 12(4), 27-31, 2004.

[6] Abou-Nassif, G.A., A Comparative Study between Physical Properties of Compact and Ring Yarn Fabrics Produced from Medium and Coarser Yarn Counts. Journal of Textiles, 1-6, 2014.

[7] Kampen, W., The advantages of condensed Spinning. Melliand Textilberichte International Textile Reports, 81(4), 58-59, 2000.

[8] Cheng, K.P.S. and Yu, C., A study of compact spun yarns. Textile Research Journal, 73(4), 345-349, 2003.

[9] Hellwig, A., Compact yarn in weaving-a new fashion or a must for high-quality fabrics? Melliand textilberichte international textile reports, 83(6), 418-419, 2002.

[10] Kretzschmar, S.D., Özgüney, A.T., Özçelik, G. and Özerdem, A., The comparison of cotton knitted fabric properties made of compact and conventional ring yarns before and after the dyeing process. Textile Research Journal, 77(4), 233-241, 2007.

[11] Abdul, S.B. and Sandip, J., Properties Evaluation of Cotton Ring and Compact Spun Yarns after Scouring and Bleaching Process. Journal of Textile Science \& Engineering, 3(3), 139, 2013.

[12] Beceren, Y. and Nergis, B.U., Comparison of the effects of cotton yarns produced by new, modified and conventional spinning systems on yarn and knitted fabric performance. Textile Research Journal, 78(4), 297-303, 2008.

[13] Dash, J.R., Ishtiaque, S.M. and Alagirusamy, R., Properties and processibility of compact yarns. Indian Journal of Fibre and Textile Research, 27(4), 362-368, 2002.

[14] Nikolić, M., Stjepanovič, Z., Lesjak, F.R.A.N.C. and Štritof, A., Compact spinning for improved quality of ring-spun yarns. Fibres\& Textiles in Eastern Europe, 4 (43), 30-35, 2003.

[15] Mavruz, S. and Ogulata, R.T., Statistical investigation of properties of ring and compact yarns and knitted fabrics made of these kinds of yarns. Tekstil ve Konfeksiyon, 18(3), 197-205, 2008.

[16] Almetwally, A.A. and Salem, M.M., Comparison between mechanical properties of fabrics woven from compact and ring spun yarns. Autex Research Journal, 10(1), 35-40, 2010.

[17] Moghassem, A.R. and Latifi, P., Properties improvement of ring spun yarn by means of a new design for front roll. Textile Sci. Technol. J, 4(2), 1-16, 2009.

[18] Kretzschmar, S.D., Özgüney, A.T., Özçelik, G. and Özerdem, A., The comparison of cotton knitted fabric properties made of compact and conventional ring yarns before and after the dyeing process. Textile Research Journal, 77(4), 233-241, 2007.

[19] Retrieved from http://www.textiletoday.com.bd/effects-of-compact-spinning -on-yarn-quality/?print=print. Accessed on 11December 2016.

[20] ASTM D 1776, Standard practice for conditioning textiles for testing," American Society for Testing and Materials, Annual Book of ASTM Standards, vol. 7(1), ASTM International, West Conshohocken, PA, USA, 2008.

[21] Retrieved from https://www.google.com/search?q=Model+2 ++ Yarn+Evenness \&ie $=$ utf-8\&oe $=$ utf- 8 \& client=firefox-b.Ac cessed on 12 December 2016.

[22] CANOĞLU, S., The Comparison of Compact (COM 4) Yarns with Conventional Ring Yarns. Marmara Journal of Pure and Applied Sciences, Special Issue-1, 71-73, 2015.

[23] Uster Technologies AG, Switzerland. Uster Tester 4-SX, 2004.

[24] S. Ibrahim, J. Militky, D. Kremenakova and R. Mishra, Characterization of yarn diameter measured on different, RMUTP International Conference: Textiles \& Fashion, Thailand, July 3-4, 2012. 